\title{
КЛИНИЧЕСКИЙ СЛУЧАЙ САХАРНОГО ДИАБЕТА, С МАНИФЕСТАЦИЕЙ ПОСЛЕ АЛЛОТРАНСПЛАНТАЦИИ ПОЧКИ
}

\author{
${ }^{1}$ Сорокин Д.Ю., ${ }^{1}$ Кураева Т.Л., ${ }^{2}$ Сибякина А.А., ${ }^{1}$ Джамалудинова А.А., ${ }^{1}$ Лаптев Д.Н. \\ ${ }^{1}$ ФГБУ «Национальный медицинский исследовательский центр эндокринологии» Минздрава \\ России, Москва
}

${ }^{2}$ ФГБУ «Федеральный научный центр трансплантологии и искусственных органов имени академика В.И. Шумакова» Минздрава России, Москва

Введение: Посттрансплантационный сахарный диабет (ПТСД) - это повышение гликемии (соответствующее критериям СД), впервые выявленное в течение 1 года после трансплантации солидного органа.

У взрослых ПТСД является частым и актуальным осложнением в посттрансплантационном периоде, включая трансплантации почек. По данным зарубежных работ, в среднем распространенность ПТСД составляет 10-20\% у реципиентов почек и 20-40\% у реципиентов других солидных органов. Аналогичные результаты были получены в отечественных исследованиях: ПТСД развивался у $6,8-$ $22 \%$ реципиентов почки. Схемы лечения схожи с сахарным диабетом 2-ого типа, однако иммуносупрессивная терапия ускоряет развитие инсулинопотребности (за счёт выраженной инсулинорезистентности и/или деструкции бета-клеток). Учитывая высокую распространенность СД 2-ого типа во взрослой популяции, актуальным является расширение скрининговых тестов в предтрансплантационный период (контроль гликемического профиля, гликированного гемоглобина (HbA1c) и т.п.).

Существуют ограниченные публикации в мировой литературе о ПТСД в возрастной группе до 18 лет. Приводим наше наблюдение.

Материалы и методы: Пациентка В., 14 лет (2007г.p.). С рождения наблюдается по поводу врожденного поликистоза почек, с жалобами на полиурию и полидипсию. Генеалогический анамнез по заболеваниям почек не отягощен. В 1,5 года при молекулярно-генетическом исследовании ДНК на наличие мутаций в "горячих" участках гена PKHDI, приводящих к развитию аутосомно-рецессивного поликистоза почек, обнаружена мутация Thr36Met в экзоне 3 в гетерозиготном состоянии, патогенная. С раннего возраста - транзиторное повышение азотемии, метаболический ацидоз, периодически повышение АД (получала гипотензивную терапию). С 11 лет (конец 2018г.) постепенное нарастание азотемии и снижение СКФ. С декабря 2019г. начат перитонеальный диализ. В июне 2021г. (в 14 лет) проведена нефрэктомия справа, аллотрансплантация трупной почки в правую подвздошную область со стентированием мочеточника трансплантата. Течение послеоперационного периода без осложнений. Функция трансплантата удовлетворительная. Индукционная терапия базиликсимаб 20 мг, метилпреднизолон. Поддерживающая терапия: метилпреднизолон 9мг, такролимус 3 мг 2 раза в сутки, микофеноловая кислота 360 мг 2 раза в день.

После трансплантации эпизодически отмечалось повышение уровня гликемии до 8,9 ммоль/л (домашний глюкометр). С 14 октября 2021г. состояние ухудшилось, стала нарастать слабость, вялость, субфебрилитет (до 37,2С), диурез сохранен адекватно водной нагрузке, АД в норме. В общем анализе мочи глюкозурия. Госпитализирована по месту жительства. При обследовании гипергликемия до 13 ммоль/л, КЩС не контролировалось, креатинин 126 мкмоль/л. Проводилась инфузионная терапия глюкозо-солевыми растворами и инсулинотерапия. В связи с нарастанием азотемии ребенок переведён в НМИЦ трансплантологии и искусственных органов им. ак. В.И. Шумакова - исключена дисфункции нефротрансплантата, инициирована интенсифицированная схема инсулинотерапии НовоРапид и Левемир. 
Через 3 нед. девочка поступила в ФГБУ «НМИЦ эндокринологии» МЗ РФ. При поступлении: рост 149.5см (SDS роста: -1.8), вес 35 кг, ИМТ 16.2 кг/м2 (SDS ИМТ -1.53), Таннер 3-4 (В 3, Р 4), Ме с января 2021 (13 лет), нерегулярные. Кожные покровы: множественные высыпания на лице в виде асnе vulgaris, бледные стрии на бедрах с обеих сторон. Диагностирована анемия лёгкой степени (гемоглобин 106 г/л (115-150)), дислипиемия (общий холестерин 5,64 ммоль/л (3,3-5,2), ЛПНП 3,62 мкмоль/л (1,10-3,00), триглицериды 2.53 ммоль/л (0.1-1.7)). HbA1c - 9,9\%. По данным пробы с завтраком (60г углеводов, контроль 0-60-120 мин) отмечается сохранная секреция С-пептида: гликемия 5.1-10.0-9.1 ммоль/л, С-пептид 2.9-6.6-6.2 нг/мл. Специфические панкреатические аутоантитела: IA-2 -1,1 Ед/мл (до 10), GADA - 0.3 Ед/мл (до 5), ZnT8 - в работе. Суточная потребность в инсулина 55-60 ЕД/сут (1.5-1.7 ЕД/кг/сут).

По данным УЗИ щитовидной железы - подозрение на аутоиммунный процесс, узловое образование правой доли щ/ж (нельзя исключить гиперплазированную паращитовидную железу), гиперплазия левой верхней паращитовидной железы. Проведена ТАБ, по результатам цитологического исследования пунктата - доброкачественное образование щитовидной железы (Bethesda: II); ПТГ (смыв иглы справа) - 5.000 пг/мл. Тиреоидный профиль, АТ к ТПО, уровни ПТГ и ионизированного кальция крови в пределах референсных значений. Гиперплазия паращитовидных желез, очевидно, носит вторичный характер на фоне длительно существующей почечной патологии.

До лета 2014г. девочка наблюдалась по поводу фиброза печени с расширением воротной вены до 0,65 см (METAVIRF3). При настоящем обследовании по данным УЗИ органов брюшной полости без прогрессирования.

Вопрос о механизме развития ПТСД у детей остаётся открытым. Особенностью данного случая является наличие основного заболевания - врожденного поликистоза почек с последующим после трансплантации развитием сахарного диабета, что в детском возрасте наблюдается достаточно редко. В этой связи нельзя исключить сочетание моногенной формы сахарного диабета MODY5, в состав которой входит, кроме инсулинзависимого сахарного диабета, поликистоз органов мочевыводящей системы.

Выводы: учитывая редкую встречаемость ПТСД в детской популяции, необходимо дальнейшее накопление случаев ПТСД (по возможности с предтрансплантационной оценкой).

Ключевые слова: сахарный диабет, дети, посттрансплантационный сахарный диабет

Информация о контактном лище: Сорокин Даниил Юрьевич, аспирант института детской эндокринологии, ФГБУ “Национальный медицинский исследовательский центр эндокринологии” Минздрава России, Москва.

Телефон: +7-927-130-56-91

E-mail: daniilsorokin007@gmail.com 